\title{
As (im)pressões do aprendente no processo de apropriação do português língua estrangeira: proficiência e alternância de línguas em rota de colisão
}

Francisco Arimir Cunha Filho ${ }^{a}$

José Carlos Chaves da Cunha ${ }^{b}$

\begin{abstract}
Resumo
Estudos sobre heterogeneidade linguístico-cultural nas aulas de lingua estrangeira têm ajudado docentes a adequarem suas práticas de ensino às especificidades de um público plurilingue e pluricultural. Todavia, no contexto do Português Língua Estrangeira (PLE), este fenômeno tem sido estudado sobretudo do ponto de vista cultural, deixando à margem a outra face igualmente importante dessa heterogeneidade: a linguística. Nossa proposta aqui é apresentar os primeiros resultados de uma pesquisa, de cunho etnográfico, voltada para a realidade plurilingue de uma turma de PLE da Universidade Federal do Pará. Os dados coletados na forma de entrevista (dos alunos) e de observação de aulas receberam um tratamento qualitativo que compreende dois momentos de reflexão: o primeiro, com foco nos aspectos contextuais da pesquisa e nos sujeitos envolvidos; o segundo, com foco na maneira como os discentes lidam com o seu repertório bi(pluri)lingue, notadamente no que concerne às suas representações linguísticas e às suas ações linguageiras. As primeiras análises apontam que a alternância de línguas é, por um lado, um dado incontornável em turmas bi(pluri)língues (embora ainda seja frequentemente olhada pelo viés da prática escondida que, se descoberta, provoca reprimenda, por parte do professor, e desestímulo por parte do aluno) e, por outro lado, um recurso didático que, devidamente gerenciado, é suscetível de tornar mais eficaz a aprendizagem da lingua-alvo (aqui, o PLE). Daí a necessidade de se levar em conta os repertórios linguísticos desses alunos, utilizando esse saber numa perspectiva aberta e dinâmica que leve à ampliação da competência comunicativa dos aprendentes na língua-alvo.
\end{abstract}

Palavras-chave: Didática do plurilinguismo. Alternância de línguas. Heterogeneidade linguística. Ensino de PLE. 


\section{Introdução}

${ }^{1}$ A partir da categorização de Castellotti (2000), propomos as seguintes defin ições para caracterizar as diferentes línguas-culturas com as quais lidam professores $\mathrm{e}$ aprendentes no processo de ensino-aprendizagem: (1) Língua materna (LM), Língua primeira, Língua de origem: referente à aquisição na infância e praticada no seio familiar, ou ainda, a primeira língua que vem à mente, idioma funcional e identitário (2) Língua segunda (LS) designa, em contexto francófono notadamente, "uma língua que tem uma presença forte ou um status específico no ambiente considerado" ( C A S T E L L O T T I, 2000, p.26); (3) Língua estrangeira (LE): praticada por pessoas ditas estranhas à população nacional ou de outro(s) país(es), aprendida depois da língua materna, quase sempre pela submissão do indivíduo a um processo formal de ensino; (3) Línguaalvo, Língua de estudo ou de aprendizagem (LA): referente ao idioma que se quer aprender pelo processo de autoaprendizagem ou de aprendizagem formal; (4) Língua regional (LRg) e/ ou nacional (LN): idioma que é praticado em um país ou região, mas que não tem caráter de língua internacional, ou seja, o seu uso se limita a uma determinada extensão territorial; (5) Língua de referência (LR), Língua da escola ou de escolarização: língua da instituição, com forte descrição metalinguística, voltada sobretudo para as habilidades de ler e escrever; (6) Repertório verbal, Repertório linguístico: "conjunto dos recursos linguageiros aos quais pode recorrer um locutor para participar da comunicação em função das situações nas quais ele pode estar inserido" (CASTELLOTTI, 2000, p.116).
As Universidades brasileiras nos últimos anos têm recebido um grande número de estrangeiros das mais variadas nacionalidades que desejam cursar uma graduação. Para que possam fazê-lo, precisam aprender o português e provar que o dominam, submetendo-se ao Exame Celpe-Bras que lhes rende a certificação de proficiência nessa língua.

Esses sujeitos trazem consigo histórias, experiências e impressões de mundo que influenciam fortemente a aprendizagem do português. Ao se voltarem para a aprendizagem de uma língua estrangeira, trazem a reboque representações sobre o código linguístico, o modo e o ritmo de como devem aprender e, ainda, reações frente ao avanço ou à estagnação do nível de proficiência durante o processo de apropriação da língua-alvo.

Estudos sobre heterogeneidade do ponto de vista linguístico-cultural muito têm ajudado docentes a desenvolverem ações suscetíveis de darem conta de tamanha complexidade. No entanto, o fenômeno da heterogeneidade no contexto do Português Língua Estrangeira (doravante PLE) no que tange às discussões, produções científicas e metodologias tem sido estudado, em sala de aula, sobretudo pelo viés cultural. Indubitavelmente, essa reflexão é relevante haja vista que os aprendentes, que já detêm uma língua(s)-cultura(s), devem se apropriar de novas formas de dizer e de se comportar numa cultura estrangeira. Porém, a outra face dessa heterogeneidade - a linguística - é igualmente importante e precisa também ser mais estudada.

Em nossa reflexão, lançamos mão de estudos que tratam do plurilinguismo que indicam, para além da reunião de culturas, um encontro entre línguas ${ }^{1}$, uma dialogando com a outra, num processo colaborativo. Com frequência, esse fato, apesar de presente, não é tratado como um aspecto importante nas práticas de ensino.

Neste trabalho, desenvolvemos uma pesquisa de cunho etnográfico voltada para a realidade plurilíngue de uma turma de PLE. Os dados coletados na forma de entrevista recebem um tratamento qualitativo que compreende dois momentos de reflexão. No primeiro, focamos os aspectos contextuais da pesquisa e os sujeitos envolvidos. No segundo momento, 
concentramo-nos na maneira como os discentes lidam com o seu repertório bi(pluri)língue, notadamente no que concerne às suas representações linguísticas e às suas ações linguageiras.

2 O conceito do plurilinguismo tem grande relevância na abordagem acional adotada pelo Conselho da Europa para a prendizagem de línguas. É definido como o conhecimento de certo número de línguas pelo indivíduo, que não ficam rigidamente separadas quando armazenadas na memória. Pelo contrário, elas se inter-relacionam e interagem constituindo assim uma competência comunicativa integrada. Segundo as indicações d o d o c u m e n to europeu, "um locutor pode, em diferentes situações, recorrer, com desembaraço, a diferentes partes desta competência para estabelecer uma comunicação eficaz com um interlocutor e specíf ico. O s interlocutores podem, por exemplo, passar de uma língua (ou de um dialeto) para outra, explorando a capacidade de cada um deles de se expressar numa língua e compreender outra" (CONSELHO DA EUROPA, 2001, p. 23).

${ }^{3}$ Outros nomes também são apropriados para identificar esse fenômeno de troca de línguas no transcorrer de um mesmo discurso, tais como alternância de código, mixilinguismo, c o d e s w it c h i n g miscibilidade de línguas, entre outros. Apesar de haver discussões no campo da sociolinguística sobre o melhor nome para referir-se ao fenômeno indicado, ainda não são claras as eventuais diferenças conceituais entre os termos. Para nós, os nomes citados dão, todos, conta dos fatos que queremos apontar na forma de marcas transcódicas (decalques, empréstimos, interferência e sequências híbridas) (DAHLET, 2009; LÜDI; PY, 2013).

\section{Posições teóricas}

Nossas referências teóricas se embasam em duas correntes de pensamento. A primeira se ocupa de questões ligadas à identidade do sujeito bi(pluri)língue e procura entender como se dá o choque entre línguas-culturas e como ele é gerenciado pelos indivíduos. A segunda defende uma proposta de ensino que explore o repertório linguístico dos alunos para favorecer a aprendizagem de uma LE. Metodologicamente, conduzimos este estudo numa perspectiva qualitativa a partir de uma pesquisa etnográfica.

\subsection{Alternância de línguas e identidade bi(pluri)língue - cenas de heterogeneidade}

Quando lidamos com um público que se constitui de sujeitos oriundos de vários pontos do planeta, para aprender uma língua estrangeira (aqui o PLE), estamos diante de uma realidade que podemos chamar de heterogênea. Esses sujeitos que já dominam, pelo menos, uma língua-cultura, transformam a sala de aula numa autêntica "torre de Babel", onde códigos linguísticos e formas de dizer se encontram e se intercruzam, possibilitando aos discentes se referenciarem para uma nova maneira de ser e fazer discursivos. $\mathrm{O}$ fenômeno plurilíngue ${ }^{2}$ se instala tornando "necessária a tomada de consciência e o reconhecimento de suas manifestações no âmbito educativo" (DAHLET, 2009: 13).

O sujeito bi(pluri)língue apresenta características que precisam ser respeitadas para não emperrar o desenvolvimento de competências na língua-alvo. Vários estudos que tratam do plurilinguismo mostram que a primeira e mais evidente delas é a alternância de línguas ${ }^{3}$ ligada a fatores identitários (LÜDI; PY, 2013; DAHLET, 2012; CASTELLOTTI, 2000, 2001).

Entendemos aqui alternância como o agir discursivo do indivíduo bi(pluri)língue que passa de um código para outro regularmente, ou seja, a mistura ou o encontro de fragmentos de línguas diferentes presentes no mesmo discurso. Tentar 
${ }^{4}$ Vale mencionar que, para o senso comum: a) a condição do sujeito bi(pluri)língue é sempre desejável ou privilegiada; $b$ ) eles lidam com o 'apagamento' da(s) língua(s) que domina(m) de forma inevitavelmente tranquila e organizada, longe de qualquer conflito identitário ou cultural (Ver LÜDI; PY, 2013).

${ }^{5}$ Para Castellotti (2001), como para nós, os alunos possuem visões sobre o objeto língua, os interlocutores com quem interagem e o país que os recebe etc. Essas imagens são, muitas vezes, fortemente estereotipadas, o que pode incluir uma visão negativa do papel da língua-cultura de origem na aprendizagem de uma LE. A autora reconhece que essas impressões têm relação direta com fatores identitários. levar o aprendente a evitar esse traço da identidade plurilíngue é negar a sua própria condição de sujeito que se encontra numa confluência de línguas e culturas. É, pois, na alternância linguística que se expressa uma identidade nascente que não mais é aquela pautada em uma "coerência" monolíngue, mas que está em um processo identitário de entrelaçamentos do velho e do novo, do conhecido e do desconhecido. Levar os professores a reconhecer a existência dessas travessias ou pontes de si mesmo não é tarefa fácil, pois a mistura é vista como espaço de conflito, de tensão, de confusão. Logo, a saída mais conveniente é ignorar o fato, silenciando ou abafando as indesejadas entradas de línguas-culturas que o aluno já domina ${ }^{4}$.

Estamos convencidos, no entanto, de que não é mais possível fechar os olhos para a guerra identitária (não declarada) que se instala no sujeito aprendente, para esse embate que se dá entre o dever ser e o como sou/estou. Não é mais justificável aceitar o "apagamento" da(s) língua(s) que o aluno leva para a sala de aula durante a aprendizagem e o uso da nova. Este "apagamento" - aliado às pressões para a adoção exclusiva da língua-alvo na sala de aula - resulta, no dizer de Dahlet (2009, p. 26), em desequilíbrios sócio-cognitivo-funcionais, "produzindo então identidades que se caracterizam, no melhor dos casos, pela insegurança ou referências flutuantes". Os sujeitos plurilíngues diante das pressões ${ }^{5}$ que eles mesmos e os sistemas fazem, tentam reservar espaços bem delimitados para cada língua-cultura, não podendo uma "invadir" o espaço da outra. Porém, ao invés de ajudar, essa tentativa pode gerar até "esquizofrenia", já que a(s) identidade(s) antigas pode(m) aparecer sem aviso-prévio (na forma de línguas-culturas), convocada(s) a todo instante para subsidiar a chegada da recém-língua.

Como queremos que essas pressões e tensões internas, peculiares aos indivíduos plurilíngues, sejam verbalizadas e integradas, postulamos que elas façam parte do processo de apropriação de uma nova língua-cultura. Afinal, como Dahlet, sabemos que

É preciso levar em conta a vivência destas tensões, pois ela depende em boa parte do reconhecimento das identificações plurilíngues como pivô da nossa história e é dela que podemos esperar integrações plurais no futuro. Conceber as identidades plurilíngues na escala das pessoas como 
pontos de tensões, potencialmente conflituosos, aumenta as chances de aproximar a adesão plurilíngue, ao invés de afastá-la. (DAHLET, 2009, p.23)

Daí, para nós, a necessidade de tratar didática e metodologicamente a alternância de línguas e a identidade bi(pluri)língue dos alunos no âmbito de uma perspectiva plurilíngue no ensino-aprendizagem de línguas.

\subsection{Por uma perspectiva plurilíngue no ensino- aprendizagem de línguas}

Abraçar a causa plurilíngue no ensino de língua implica, por um lado, aceitar a formação de um repertório plural e diversificado (CASTELLOTTI, 2001) e, por outro lado, abrir-se aos diversos recursos disponíveis para o ensino-aprendizagem, inclusive os contributos que a(s) língua(s) e cultura(s) já adquiridas podem dar à construção desse repertório.

No que concerne à LM, Dabène (1994) indica as múltiplas funções desse repertório no plano linguístico, simbólico, afetivo, social, das aprendizagens fundamentais, constituindose como fonte capital para reflexões metalinguísticas entre dois ou mais sistemas. É a partir da LM e/ou da língua (do aluno) que mais se aproxima da língua-alvo (CUNHA; SANTOS, 2013) que cada aprendente faz hipóteses sobre o funcionamento desta última e começa, desde o início da aprendizagem, a utilizar uma interlíngua ${ }^{6}$ (CAMAROTTA; GIACOBBE, 1986 apud

6 "Em didática das línguas, designa-se por interlíngua a natureza e a estrutura específicas do sistema de uma língua alvo internalizada por um aprendente em um dado nível. Esse sistema é caracterizado por marcas da língua alvo e da língua fonte (língua materna ou outras línguas aprendidas posteriormente ou simultaneamente), sem que se possa ver nisso apenas a adição ou a mistura das duas. Tratase, de fato, de um sistema dotado de estrutura própria e que só pode ser descrito como tal" (CUQ, 2003, p. 139-140) (Tradução nossa). CASTELLOTTI, 2001). Além disso, parece que é praticamente impossível tentar controlar demasiadamente as entradas da L1 (ou outra qualquer do repertório do aprendente) ou mesmo apagá-la em sala de aula.

De fato, a partir de estudos realizados em turmas plurilíngues (CASTELLOTTI, 2001; LÜDI; PY, 2013; WANTAZBAUER, 2001), já se constatou, por um lado, que quando o nível de competência dos alunos é baixo na língua-alvo, ele recorre irremediavelmente ao seu repertório linguístico e, por outro lado, que quando há nessas turmas plurilíngues alunos que dominam uma mesma língua, estes, com frequência, lançam mão dela, ainda que desagradem ao professor. Assim, por exemplo, quando surgem dúvidas sobre um dado funcionamento da 
${ }^{7}$ Isto é, entre outras coisas, utilizar procedimentos, estratégias que tornem a sala de aula um espaço aberto ao plurilinguismo, valorizando assim a diversidade linguísticocultural, marca da identidade do falar bi(pluri)língue (MOORE; PY, 1995).

${ }^{8}$ Turmas dessa natureza têm sido oferecidos desde 2008 e visam preparar candidatos estrangeiros a prestarem o exame Celpe-Bras. Uma vez aprovados, podem cursar uma graduação numa instituição brasileira de ensino superior.

${ }^{9}$ O PEC-G oferece formação de recursos humanos a cidadãos d e país es e m desenvolvimento com os quais o Brasil se relaciona por meio de acordos culturais e educacionais para que possam cursar uma graduação numa IES (Instituição de Ensino Superior) do país. língua-alvo, um discente que compreendeu esse funcionamento ajuda seu(s) colega(s) na língua que eles já partilham.

Esse vaivém de línguas em situações de ensinoaprendizagem atende a uma diversidade de fatores. Além do já conhecido papel de compensação - pelo fato de o aluno não dominar a língua-alvo -, a alternância exerce (ou pode exercer) um papel importante, tanto nas reflexões metalinguísticas/ metalinguageiras em sala de aula, quanto na regulação do processo de ensino-aprendizagem. A alternância é, pois, suscetível de favorecer a aprendizagem. Didatizá-la ${ }^{7}$ pode contribuir para tornar mais eficaz o processo de ensinoaprendizagem de uma LE.

\section{Metodologia, contexto e sujeitos da pesquisa}

Desenvolvemos um estudo etnográfico, adotando uma abordagem qualitativa para geração e tratamento de dados. Acreditamos ser esta a forma mais adequada para lidarmos com o fenômeno apontado - a miscibilidade de línguas (mixilinguismo/plurilinguismo) no contexto de desenvolvimento de competência no PLE. A pesquisa nesses moldes favorece a investigação no ambiente pedagógico onde o português brasileiro é objeto de ensino.

André (2007, p. 27) caracteriza a referida pesquisa no âmbito da educação da seguinte maneira:

a) Utilização de técnicas tradicionalmente associadas à etnografia (observação participante, entrevista e análise de documentos); b) Interação constante entre pesquisador e objeto pesquisado, já que o principal instrumento na coleta e na análise dos dados é o pesquisador; c) Ênfase no processo e não no produto ou nos resultados finais; d) Preocupação com o significado atribuído pelas pessoas a si mesmas, a suas experiências e ao mundo; e) Coleta dos dados por meio de um trabalho de campo.

Alinhados à perspectiva acima, observamos uma turma ${ }^{8}$ de PLE que funcionou no ano de 2014 na UFPA. Ela era formada por jovens que tinham vindo estudar no Brasil no âmbito do Programa de Estudantes Convênio de Graduação (PEC-G) ${ }^{9}$, do Ministério da Educação. 
${ }^{10}$ O período de coleta de dados se estendeu por quatro meses, entre abril e agosto, totalizando 60 horas de aula, equivalente a quinze dias de observação distribuídos no período indicado.

${ }^{11}$ A entrevista foi gravada em áudio e depois transcrita.

12 No dia da semana em que concentramos nossas observações, duas professoras estagiárias trabalhavam com a turma.

13 Distribuídas em cinco dias por semana, perfazendo quatro horas/ aula para cada período.

${ }^{14}$ No início, a turma era formada por 14 alunos, porém um deles, oriundo de Trinidad e Tobago, foi convidado a fazer parte de um programa de graduação semelhante no Reino Unido e abandonou o curso.

15 Elas frequentaram escolas bilíngues durante todo o ensino fundamental e médio.

${ }^{16} \mathrm{O}$ domínio do inglês não era completo apenas por parte dos alunos do Benim, que apresentavam alguma dificuldade nas competências de produção e de compreensão oral, mas não tinham dificuldade alguma no âmbito da compreensão escrita. Isso se deve ao fato de que o inglês é a LE de ensino no sistema educacional daquele país.
Para nosso registro, utilizamos entrevistas com os alunos, seguindo um questionário ${ }^{10,11}$. Inicialmente queríamos verificar apenas como se dava a dinâmica de ensino praticada pelas professoras ${ }^{12}$ e as interações entre os sujeitos. Porém, nesse processo, chamou-nos muita atenção um fato que se repetia com bastante frequência. Nenhum dos alunos havia tido contato com o português antes de vir para o Brasil. Recorrentemente, os discentes falavam nas suas LM e/ou LS e/ou LE com os seus iguais haja vista o domínio do português ser ainda bem limitado - embora já tivessem três meses de estudo, com uma carga horária de 20 horas semanais ${ }^{13}$. As professoras tentavam coibir esse uso, tanto que, na primeira vez em que presenciamos uma dessas tentativas, uma delas até incluiu um de nossos pesquisadores na repreensão por ter falado em outra língua que não o português com um dos alunos. Para nós, esse procedimento não levou a lugar algum, pois, na verdade, os alunos apenas reduziam o volume de suas vozes, o que não evitava novos pedidos das professoras para acabar com essa prática.

Este fato foi determinante para focarmos nosso olhar nas entrevistas, tornando clara a necessidade de ouvir os discentes para sabermos, entre outras coisas, o que sentiam por não poderem se comunicar durante as aulas em sua L1 e/ou L2.

Bem heterogênea, a turma era formada por 13 alunos $^{14}$, sendo quatro de Gana, quatro de Honduras, quatro do Benim e um do Congo. Respectivamente, formavam três grandes grupos linguísticos quanto à LR, a saber, inglês, espanhol e francês. Todos, sem exceção, eram, no mínimo, bilíngues. Os alunos de Gana, além de dominarem a LR, falavam pelo menos mais duas línguas regionais e/ou nacionais. As quatro alunas hondurenhas eram bilíngues, pois falavam a língua espanhola e, fluentemente, o inglês ${ }^{15}$. Os alunos do Benim tinham um perfil linguístico muito semelhante ao dos ganeses: dominavam a língua da instituição e mais duas ou três línguas regionais, e ainda tinham boas noções de inglês.

A partir do percurso escolar de cada um, foi possível perceber que, apesar da grande heterogeneidade, todos tinham em comum a língua inglesa, ainda que alguns não a dominassem bem ${ }^{16}$. 
Quadro 1. Turma PLE/PEC-G 2014 - UFPA ${ }^{17}$

\begin{tabular}{|c|c|c|c|c|c|}
\hline APRENDENTE & NACIONALIDADE & IDADE & $\mathbf{L M}$ & LS & LE \\
\hline HOND-1 & Hondurenha & 19 & Espanhol & - & $\begin{array}{l}\text { Inglês e } \\
\text { Português }\end{array}$ \\
\hline HOND-2 & Hondurenha & 19 & Espanhol & - & $\begin{array}{l}\text { Inglês e } \\
\text { Português }\end{array}$ \\
\hline HOND-3 & Hondurenha & 19 & Espanhol & - & $\begin{array}{c}\text { Inglês, Francês } \\
\text { e Português }\end{array}$ \\
\hline HOND-4 & Hondurenha & 19 & Espanhol & - & $\begin{array}{c}\text { Inglês e } \\
\text { Português }\end{array}$ \\
\hline GANA-1 & Ganense & 22 & Tchwi / Akan & Inglês & Português \\
\hline GANA-2 & Ganense & 20 & $\begin{array}{c}\text { Tchwi / } \\
\text { Akan, Fante, } \\
\text { Ga, Mina/ } \\
\text { Ewe }\end{array}$ & Inglês & Português \\
\hline GANA-3 & Ganense & 20 & Tchwi / Akan & Inglês & Português \\
\hline GANA-4 & Ganense & 23 & Tchwi / Akan & Inglês & Português \\
\hline BENI-1 & Beninense & 20 & $\begin{array}{c}\text { Fon, Goun, } \\
\text { Adja, } \\
\text { Kolafon } \\
\text { Mina/Ewe, }\end{array}$ & Francês & $\begin{array}{c}\text { Inglês e } \\
\text { Português }\end{array}$ \\
\hline BENI-2 & Beninense & 23 & $\begin{array}{l}\text { Fon, Goun, } \\
\text { Dendi }\end{array}$ & Francês & $\begin{array}{l}\text { Inglês e } \\
\text { Português }\end{array}$ \\
\hline BENI-3 & Beninense & 23 & Fon & Francês & $\begin{array}{c}\text { Inglês e } \\
\text { Português }\end{array}$ \\
\hline BENI-4 & Beninense & 22 & Fon & Francês & $\begin{array}{l}\text { Inglês e } \\
\text { Português }\end{array}$ \\
\hline CONG-1 & Congolesa & 20 & $\begin{array}{l}\text { Lari, Lingala, } \\
\text { Munukutuba }\end{array}$ & Francês & $\begin{array}{l}\text { Inglês e } \\
\text { Português }\end{array}$ \\
\hline TRIN-1 & Trinidense & 24 & Inglês & - & Português \\
\hline
\end{tabular}

Outra característica comum a esse grupo de alunos era o fato de nunca terem imaginado um dia vir para o Brasil. Nenhum deles tivera antes contato com o português e/ou

${ }_{17}$ Elaborado pela equipe do GEALC (Grupo de Ensino-Aprendizagem de Língua-Cultura) da UFPA. tinha planejado aprender nossa língua-cultura. Chegaram em nosso país sem falar uma palavra de nosso idioma e sem conhecer quase nada de nossa cultura. Uma estudante ganesa 
chegou a dizer: "eu queria mesmo era ir para Londres, mas o Brasil foi o que aconteceu". Quando perguntados sobre o que conheciam da cultura brasileira, apenas responderam que ouviam falar de futebol e de Michel Teló, cujas músicas, aliás, eram cantadas na língua oficial de seu país na voz de outro intérprete. Digno de menção também foi o fato de que os aprendentes oriundos do mesmo país só tiveram contato uns com outros no voo para o Brasil.

Um fato bastante recorrente, observado durante as interações em sala de aula, foi o semblante de incompreensão por parte da maioria dos estudantes africanos. Não por acaso, eram as alunas hispânicas que, no mais das vezes, ficavam encarregadas das atividades de exposição oral. Mesmo que se possam aventar questões ligadas à timidez, muito comum nas atividades orais, todos os africanos disseram que entendiam a necessidade de se manifestar e que não se negavam a executar tal tipo de tarefa, uma vez que esse tipo de atividade fazia parte de sua aprendizagem. Ainda assim apenas dois deles tentavam se expressar em português. A este respeito, chamou-nos a atenção o que disse uma aluna ganesa: "Eu simplesmente não consigo, não sei falar português".

Perguntamos então se eles achavam o português uma língua difícil. Dos quatro alunos anglófonos, dois disseram que não e dois afirmaram que sim. Mas todos concordaram que a dificuldade de falar português se devia, sobretudo, às conjugações complicadas e às complexas questões ligadas ao gênero das palavras. Esta última resposta desvela, por parte desses alunos, uma concepção bastante gramatical do funcionamento linguageiro, o que, sem dúvida, pode emperrar a desenvoltura deles para agir discursivamente. Já os quatro falantes hispânicos e os cinco falantes francófonos afirmaram unanimemente que o português é fácil ou, pelo menos, não é muito difícil.

A pergunta seguinte que fizemos aos discentes está ligada à anterior, porém as respostas fornecidas ganharam um rumo que não é meramente linguístico. Indagamos sobre o que é mais difícil fazer em português (escrever, ler, ouvir ou falar). Todos os alunos apontaram que as habilidades ligadas à oralidade (falar e ouvir) eram as mais complicadas. $\mathrm{O}$ fato de não incluírem nessa lista as habilidades ligadas à escrita, 
certamente vem confirmar o que já havíamos observado em sala de aula: a tendência para reduzir o uso da língua ao mero conhecimento da engrenagem linguística. Esta, nas produções escritas, é mais facilmente percebida e o seu conhecimento pode ser determinante para se apreender o sentido, o que lhes permite, às vezes, consciente ou inconscientemente, minimizar a influência de outros fatores - como o contextual, por exemplo - bem mais determinantes na oralidade.

Os cinco alunos francófonos (quatro beninenses e um congolês) acharam que ouvir é o que há de mais difícil no português, alegando que os brasileiros não abrem bem a boca ou pronunciam tudo rápido demais. Nenhuma razão linguística foi fornecida. Das quatro alunas hispânicas, uma concluiu que ouvir é mais difícil, pois a velocidade da fala e os sotaques atrapalham a compreensão. As outras três consideraram que falar é o problema: o sotaque e a influência do espanhol no momento da produção oral dificultam o desempenho delas. Já três dos quatro ganenses (anglófonos) apontaram que a atividade mais desafiadora era falar em português. O outro disse ser a compreensão oral. Entre as razões apontadas por esses últimos para suas dificuldades de compreensão ou de produção oral estão o vocabulário reduzido e a rapidez da fala dos brasileiros.

Até aqui, apresentamos dados relativos ao contexto da pesquisa e aos sujeitos aprendentes (condições de aprendizagem, representações que têm da língua com a qual estão lidando). Passaremos agora a analisar como eles reagiram às flutuações entre a língua-alvo (português) e as línguasculturas representadas na sala de aula levando em conta o contexto desfavorável para o uso destas últimas.

\section{Alternância de línguas em rota de colisão: choques entre o dizer e o fazer}

Procuramos analisar nesta seção como a alternância linguística e o contato de línguas são percebidos pelos alunos e como eles lidam com o material linguístico do qual já se apropriaram (ou estão se apropriando).

Primeiramente, queríamos perceber se eles estavam atentos às relações linguísticas entre os idiomas e perguntamos para os três grupos de alunos se o português apresenta 
semelhanças com sua L1 ou LR e, em caso afirmativo, se isso era uma vantagem ou uma desvantagem. Para o grupo de anglófonos, os quatro alunos ganeses responderam que há vocábulos em sua língua nacional (o tchwy) semelhantes a vocábulos do português (Ex. copo, forno, pão etc.). Quando perguntados se o inglês apresenta similaridades com o português, num primeiro momento todos disseram que não havia nada em comum entre as duas línguas. Como insistimos na pergunta eles começaram a dizer que há palavras de mesma origem que deve seguir um mesmo padrão. Vejamos alguns depoimentos ${ }^{18}$ a esse respeito:

\begin{tabular}{|c|c|}
\hline GANA-1 & GANA-04 \\
\hline GANA-1: Algumas palavras. & ENTREVISTADOR: Inglês parece? \\
\hline ENTREVISTADOR: Tipo? & GANA-4: Inglês parece um pouco porque \\
\hline $\begin{array}{l}\text { GANA-1: Tipo, palavras em inglês que tipo, } \\
\text { university em inglês. }\end{array}$ & $\begin{array}{l}\text { eu ler um documento que fala que inglês e } \\
\text { português têm } 1060 \text { palavra em comum }\end{array}$ \\
\hline ENTREVISTADOR: Tá, tá, palavras cognatas & ENTREVISTADOR: Certo \\
\hline GANA-1: Cognatas! & $\begin{array}{l}\text { GANA-4: Por exemplo, todas as palavras em } \\
\text { inglês que acabar em ty em português é ti. }\end{array}$ \\
\hline ENTREVISTADOR: Parecidas & dade. Por exemplo, univerty universidade, \\
\hline GANA-1: Vai mudar é universidade & hability habilidade. E muitas palavras, hospital \\
\hline ENTREVISTADOR: Sei, sei. & muitas palavras. \\
\hline GANA-1: Unity em português é unidade & \\
\hline ENTREVISTADOR: Certo, certo. & \\
\hline
\end{tabular}

${ }^{18} \mathrm{O}$ registro das falas presentes neste artigo segue as orientações de Marscuschi (2001) na tentativa de reproduzir fielmente a forma como os depoentes se expressaram.
Aqui as observações feitas pelos próprios alunos indicam que as convergências notadas são apenas aquelas que estão no nível lexical. Quando indagados se percebiam semelhanças entre a gramática do português e a de sua LM ou LR, a resposta dada por todos foi que não havia. Apesar de nossa insistência para que verificassem se, realmente, não havia nenhuma semelhança entre elas, eles consideraram que se tratava de duas línguas muito diferentes. Percebemos aí o quanto essas relações podem e devem ser mais bem exploradas já que tanto o português quanto o inglês guardam características comuns bem marcadas em vários estratos entre os dois sistemas. Além disso, as diferenças entre as línguas também podem ser usadas 
para ajudar no entendimento do funcionamento da língua-alvo, fornecendo padrões diferentes da(s) língua(s) já dominada(s) que, por extensão, podem dar uma visão mais consciente e clara tanto da língua de origem (ou de referência), quanto da língua de aprendizagem.

As quatro alunas de língua hispânica afirmaram que o português é bem parecido com o espanhol. Quanto a considerar se isso é uma vantagem ou desvantagem as discentes concordaram que, sem dúvida, tal similitude era positiva, mas apenas no início do processo de aprendizagem. Vejamos o que duas delas disseram a esse respeito:

\begin{tabular}{|l|l|}
\hline \multicolumn{1}{|c|}{ HOND-1 } & \multicolumn{1}{|c|}{ HOND-4 } \\
\hline $\begin{array}{l}\text { HOND-1: A desvantagem é o que como se } \\
\text { sabe que são muita é português e espanhol } \\
\text { tem muita semelhança. }\end{array}$ & $\begin{array}{l}\text { ENTREVISTADOR: Muito, né? Isso é uma } \\
\text { vantagem ou é uma desvantagem? } \\
\text { ENTREVISTADOR: Certo. }\end{array}$ \\
$\begin{array}{l}\text { HOND-4: É uma pequena vantagem, mas } \\
\text { misturando palavras, entendeu? }\end{array}$ & $\begin{array}{l}\text { é uma grande desvantagem, porque você } \\
\text { tende a confundir as línguas, muito muito }\end{array}$ \\
ENTREVISTADOR: Hum, hum. & $\begin{array}{l}\text { fácil [...] } \\
\text { ENTREVISTADOR: Certo. }\end{array}$ \\
$\begin{array}{l}\text { HOND-1: Ficamos misturando palavras, e } \\
\text { como te falei depois terminamos falando } \\
\text { portunhol. }\end{array}$ & $\begin{array}{l}\text { HOND-4: Eu acho que também é isso } \\
\text { porque são tão parecidas que você tende a } \\
\text { confundi-las. }\end{array}$ \\
\hline
\end{tabular}

Os cinco alunos francófonos (quatro do Benim e um do Congo) entendem que as semelhanças entre o português e o francês são tênues. Apenas um dentre eles considera que as duas línguas são parecidas. Identificam alguns traços que as aproximam, mas nada que os faça ter a mesma sensação que as hispânicas. No entanto, quando perguntados sobre se essa (pouca) semelhança entre as duas línguas poderia ajudá-los a aprender o português mais facilmente, afirmaram que o francês favorecia a compreensão oral. Foi o que disse, por exemplo, um dos alunos do Benim: 


\section{BENI-1}

ENTREVISTADOR: O português não parece nem com o fon nem com o gun, mas ele parece com o francês?

BENI-1: Sim.

ENTREVISTADOR: Muito ou pouco?

Alben1: Pouco

ENTREVISTADOR: Pouco, isso é uma vantagem ou uma desvantagem?

BENI-1: Uma vantagem.

ENTREVISTADOR: Por que é uma vantagem?

$[\ldots]$

BENI-1: Quando as professoras pronunce as palavras eu me lembro do

ENTREVISTADOR: Do francês.

BENI-1: Do francês.

Perguntamos em seguida aos estudantes se usavam os conhecimentos que têm das línguas que dominam, principalmente das LR. Todos, independentemente da origem, responderam afirmativamente à questão sem relutar. Os ganenses disseram que usam basicamente o conhecimento que têm do repertório lexical inglês. Houve ainda um aluno que arriscou dizer que o som de algumas palavras de sua língua nacional (o tchwy) soa como o português. Nesse grupo de alunos, dois depoimentos indicam como eles fazem um trabalho entre línguas para compreender ou produzir em português.

\begin{tabular}{|c|c|}
\hline GANA-3 & GANA-4 \\
\hline $\begin{array}{l}\text { ENTREVISTADOR: Você usa? } \\
\text { GANA-3: Uso } \\
\text { ENTREVISTADOR:[...] quando é } \\
\text { que você usa o inglês pra te ajudar a } \\
\text { entender português? } \\
\text { GANA-3: Quando eu estou, quando } \\
\text { eu quero ler, quando algumas pessoas } \\
\text { fala, eu tra, translate. } \\
\text { ENTREVISTADOR: Você traduz. } \\
\text { GANA-3: Eu traduz inglês. }\end{array}$ & $\begin{array}{l}\text { GANA-4: Quando eu, eu não sei como explicar. } \\
\text { O tempo [...] por exemplo a gente tem particípio } \\
\text { de futuro e outras coisas [...] eu quero falar eu, } \\
\text { antigamente não consegui diferenciar de ela sentou } \\
\text { lá e ela sentado lá, sentou e sentado, eu percebo que as } \\
\text { duas passado, mas em inglês tem duas significado, } \\
\text { shesittedthere, que é ela sentou lá e, desculpa, } \\
\text { shesatthere, ela sentou lá. E she sitted there [...] } \\
\text { mulhersentavalá, sentava, a mulhersentadolá [...] } \\
\text { the woman sat there and the woman sitted there [...] } \\
\text { ENTREVISTADOR: Entendi, você faz comparações. } \\
\text { GANA-4: Sim, comparações english e ajuda muito. }\end{array}$ \\
\hline
\end{tabular}


Aqui parece claro que o diálogo entre línguas (português e inglês) ocorre de maneira bem intensa, na forma de tradução e de atenção às equivalências entre categorias comuns. Essa atitude é elogiável, porém, se não for bem gerenciada e dosada, pode emperrar o sucesso de um ensino mais comunicativo.

Igualmente, as alunas hondurenhas disseram que usam o espanhol e o inglês para ajudá-las no processo de descoberta do português, fazendo comparações entre os idiomas. Para elas, o inglês amplia o vocabulário e o conhecimento do léxico, e o espanhol ajuda na conjugação verbal, principalmente em relação ao pretérito e à estruturação das orações.

Já os alunos que falam francês, além de usarem o recurso de tradução, lançaram mão também da análise contrastiva em aspectos bem interessantes, conforme se pode constatar abaixo:

\begin{tabular}{|c|c|}
\hline BENI-2 & CONG-1 \\
\hline $\begin{array}{l}\text { BENI-2: [...] tem, por exemplo, a pessoa, se } \\
\text { você não sabe e... a... os artigos que você } \\
\text { vai colocar lá, você pode colocar artigo de } \\
\text { francês, porque é um pouco similar. } \\
\text { ENTREVISTADOR: Certo. } \\
\text { BENI-2: sim, porque a cadeira, é, a cadeira } \\
\text { é... lachaise [...] em francês, então "a" é } \\
\text { igual "a" aqui [...] e "le" é igual a "o" aqui } \\
{[\ldots . .] \text { então se você não pode, você não sabe }} \\
\text { o artigo que você vai colocar lá }[. . .] \text { você } \\
\text { vai buscar no francês. }\end{array}$ & $\begin{array}{l}\text { CONG-1: Eu... pego o estilo, por exemplo pra } \\
\text { formar uma frase em francês. } \\
\text { ENTREVISTADOR: Certo } \\
\text { CONG-1: sujet, sujet. } \\
\text { ENTREVISTADOR: sujeito. } \\
\text { CONG-1: sujeito, verbo, complemento [...] é } \\
\text { maneira de nós falar, eu pego essa maneira me } \\
\text { ajuda a falar. }\end{array}$ \\
\hline
\end{tabular}

Fizemos desta vez uma pergunta que se liga ao uso da(s) língua(s), indagando se misturavam as línguas durante suas tentativas de falar português e o que achavam dessa situação. Neste quesito, as respostas dadas vão sempre na mesma direção. Primeiramente, todos, sem exceção, reportaram que misturavam e que era quase sempre impossível não misturar. Aliás, durante nossas interações, eles riram de sua condição ainda instável de proficiência, autênticos "misturadores de línguas". Em geral, eles justificaram essa miscelânea códica pelo fato de não possuírem ainda um bom domínio do português e por recorrerem à língua de referência como uma medida de emergência para suprir a falta de uma palavra, por exemplo. Porém, reconheceram que esse recurso só é interessante 
quando o interlocutor tem essa língua em comum. As alunas hispânicas disseram que misturam, pois às vezes pensam que estão falando português, mas, depois de certo tempo, se dão conta de que estavam, na realidade, falando espanhol.

Alguns alunos apontaram ainda outras razões para a mistura entre línguas, razões essas vinculadas a fatores identitários e de representação. Por exemplo, uma aluna de Gana diz que em sua região se usa a língua regional quando se quer contar algum segredo. Outra ganense argumenta que cresceu falando inglês: "o português é algo muito novo para mim, num é da noite por dia que vou mudar". Na avaliação de todos eles, a mistura é vista muito negativamente, porque ela dificulta a comunicação com os nativos brasileiros e, ainda, porque há pressões institucionais que impõem o uso da norma culta. Os dois depoimentos são reveladores desse sentimento de desaprovação da mescla linguística.

\begin{tabular}{|c|c|}
\hline HOND-4 & BENI-2 \\
\hline $\begin{array}{l}\text { ENTREVISTADOR: Misturar é uma } \\
\text { vantagem ou uma desvantagem? } \\
\text { HOND-4: Desvantage, desvantagem, porque } \\
\text { você vem pra cá para aprender português, } \\
\text { não pra aprender uma mistura de as língua }\end{array}$ & $\begin{array}{l}\text { BENI-2: Porque pra escre, nós queremos ir } \\
\text { mal não uma prova, então se você misturar } \\
\text { lá, o coreto, pode conseguir compreender } \\
\text { o que você está escrevendo o que você tá } \\
\text { falando, então é muito ruim. }\end{array}$ \\
\hline
\end{tabular}

A pergunta seguinte tratou da proibição das LM e/ou LR durante as aulas. Primeiro, procuramos saber se era verdade que eles não podiam usar essas línguas em sala de aula. Todos responderam que, de fato, não podiam usá-las. Depois, perguntamos se concordavam com essa proibição. Talvez internalizando o discurso da maioria dos professores, os alunos afirmaram que, de um modo geral, a medida era boa ou muito boa. Entre as principais razões apresentadas para tal adesão foi mencionado o objetivo pelo qual vieram ao Brasil: aprender português e passar no exame Celpe-Bras. Mas outras razões, como a de HOND-4 e a de CONG-1, também foram apontadas:

\begin{tabular}{|l|l|}
\hline \multicolumn{1}{|c|}{ HOND-4 } & \multicolumn{1}{|c|}{ CONG-1 } \\
\hline $\begin{array}{l}\text { HOND-4: É bom porque quando sempre nós } \\
\text { falamos português, é uma, é uma, é também } \\
\text { uma soli, solução para nós, para melhorar } \\
\text { nossa, nosso nível. }\end{array}$ & $\begin{array}{l}\text { CONG-1: Porque como eu quero aprender } \\
\text { uma língua e me proibir de não falar essa } \\
\text { língua por mim é para meu bem. }\end{array}$ \\
\hline
\end{tabular}


Como acompanhávamos o curso, sabíamos que os alunos misturavam línguas na sala de aula, apesar da proibição de vários professores. A reação de dois alunos ganeses foi interessante, pois pareceram entender que éramos uma espécie de polícia didática, levando-os a denunciar casos de desobediência flagrante. Por exemplo, reportaram que as alunas hondurenhas falavam muito espanhol e os francófonos falavam muito francês durante as aulas. De alguma forma, essa 'delação' funcionou como desculpa para o fato de que eles falavam inglês entre si durante as aulas. Pouco tempo depois, os quatro alunos ganenses admitiram que conversavam muito em inglês e em sua língua nacional durante as aulas. O grupo de hispânicas afirmou que se tratava de uma regra impossível de ser cumprida. Os alunos francófonos admitiram por sua vez que, como os outros, também não seguiam essa regra à risca.

Entre as razões fornecidas para explicar a desobediência, alguns disseram que muitas vezes não compreendiam bem uma explicação dada pelo professor. Uma aluna de Honduras chegou a afirmar o seguinte: "o problema é que o português não tem regra, quando elas (professoras) não sabem como explicar aos meninos que falam inglês, então nós falamos coisas que podem ajudar a eles a mais ou menos ter uma ideia". Em outras palavras, como boa parte dos professores só usa a língua-alvo na sala, e nem sempre fornece explicações claras para um dado funcionamento linguageiro, fica a impressão, para alguns aprendentes, que "o português não tem regra". Aqueles que conseguem perceber alguma norma ajudam seus iguais por meio de uma língua que não o português, mesmo que isso signifique burlar uma proibição. Uma segunda razão é o fato de que recorrer à LM ou à LR é uma saída bem econômica, quando se quer dar uma informação rápida ou fazer as coisas ficarem em segredo.

Outra pergunta que fizemos aos alunos durante as entrevistas centrou-se no fato de a LR deles poder ser usada para explicar um dado funcionamento do português quando houvesse dificuldades de compreensão usando apenas a línguaalvo. Doze alunos concordaram que seria bom usar a língua que dominam em casos de pouca ou nenhuma compreensão de regras morfossintáticas. Um aluno discordou da maioria dizendo que, se estava estudando português, a explicação deveria ser dada sempre em português, não importando se o 
aluno entendeu ou não. Aqueles que concordaram manifestaram que se deve tentar ensinar primeiro em português e só usar outra língua quando tiverem esgotado todos os recursos na língua-alvo. Percebemos, porém, que mesmo quando todos os recursos se esgotavam, nem a LM, nem a LR eram usadas para sanar dúvidas dos aprendentes. Isso ficou claro na fala de uma aluna ganense: "mas professor, não... não deixa (referindo-se a ele não explicar em sua língua) [...] porque eu quero expressar, eu não entendi a palavra em português. Então ele must...ele deve explicar em inglês, em inglês". Ainda a esse respeito, outro aluno contou um caso ocorrido durante as aulas com os alunos de língua inglesa que não tinham compreendido quando se usa "para" e "por". As professoras tentaram, sem sucesso, explicar em português. Até que HOND-2, que também fala inglês, explicou nessa língua o uso dos termos em português e foi compreendida por seus interlocutores.

\section{HOND-2}

HOND-2: Nós entendemos porque no espanhol é a mesma coisa, mas os que falam inglês não tem essa mesma forma, então nós é... tentamos ajudar um pouco, e pra como seria uma forma de explicar usando o inglês, não é exatamente o mesmo, mas acho que ajudou um pouco. Por isso pode ser usado.

Uma aluna de Gana concordou com HOND-2: "eu ainda estudando português e eu não sei muitas coisas [...] então quando alguma palavra é difícil pra mim entender, eles podem usar english".

Nossa última indagação aos discentes foi se eles achavam importante o professor conhecer sua LM ou LR. Todos, à exceção de um aluno, afirmaram que contar com um professor que domine uma língua comum à deles é algo bom. Três estudantes ganenses justificaram seu posicionamento dizendo que, assim, teria suas dúvidas tiradas mais rapidamente, sobretudo no início do curso. As hondurenhas disseram que se os professores soubessem espanhol entenderiam melhor suas dificuldades e as ajudariam a avançar mais depressa. A fala de uma delas é bem significativa a esse respeito: 


\section{HOND-4}

HOND-4: Porque ele vai saber qual são as nossas necessidades, nossas vontades, as coisas que nós vai confundir, coisas que vai entender, como, por exemplo, talvez hay um tema que ele tenta explicar, mas se ele sabe que essa coisa é a mesma coisa em espanhol, ele não tem que ter gastar o tempo isso, mas se ele sabe que essa coisa é diferente com espanhol, ele vai esforçar-se mais para explicar esse tema

Finalmente, para o grupo francófono, se os professores soubessem falar francês haveria "uma espécie de duplo intercâmbio", no sentido de que as trocas linguísticas poderiam acontecer com mais frequência para apoiar o início da aprendizagem e, também, para falar de outras coisas e não só de aprender português.

\section{Encarando o desafio de mundos em choque}

O que expusemos e analisamos aqui revela uma realidade ignorada ou mal gerenciada por muitos professores de PLE em nosso país. Encarando-a de frente, percebemos que, em turmas plurilíngues, é praticamente impossível impedir a alternância linguística em sala de aula. Ademais, não parece viável, nem eficaz tentar fazer tabula rasa da LM e da LR dos aprendentes com o propósito de coibir o uso de outras línguas para favorecer a apropriação da língua-alvo. Trabalhamos e convivemos com gente e gente possui identidade, representações, hábitos etc. que foram sendo constituídos e internalizados na(s) e pela(s) línguas-culturas que cada um domina. Por isso, pelas falas dos discentes, pelo que já vivemos e observamos em sala de aula, as misturas de línguas mostram claramente que se trata de uma prática impossível de se apagar, o que nos leva não somente a reconhecer a existência do fenômeno, mas também a querer aprofundar a sua análise no âmbito do ensino-aprendizagem do PLE.

Ficou claro também para nós que a alternância linguística não pode ser olhada pelo viés da marginalidade, isto é, da prática escondida que, se descoberta, provoca reprimenda, por parte do professor, e desestímulo por parte do aluno. Concebemos o desenvolvimento de competência em LE como um processo, com tudo o que isso implica, precisamos, pois, levar em conta a realidade dos sujeitos envolvidos, notadamente 
o fato de que eles misturam a língua-alvo com sua LM e/ou com outra língua de seu repertório que seja mais parecida com a que estão aprendendo. Ignorar esse fato pode dificultar - como dificultou para alguns - a apropriação da língua-alvo.

A alternância linguística faz parte do processo de aprendizagem. Deveria, portanto, ser qualificada e 'explorada' didaticamente. Mas parece que ainda é muito forte no discurso instituciona ${ }^{19}$ a concepção de que misturar é ruim, tanto que muitos alunos acabam internalizando esse discurso achando que somente a língua-alvo pode ser usada durante as aulas, que seu capital plurilíngue atrapalha a aprendizagem de uma LE. Tentam-se impedir as manifestações plurilíngues em sala de aula com base apenas nessa crença. Mas é uma tentativa vã porque os alunos não conseguem evitar o uso de seu repertório linguístico e burlam, consciente ou inconscientemente, em suas falas, a ordem de não misturar.

Consideramos igualmente equivocado relegar as ocorrências da mistura de línguas a um plano secundário, logo suscetível de ser ignorado pelos professores e pesquisadores. Trata-se, na verdade, de um fenômeno complexo cujo impacto na sala de aula precisa ser mais estudado e mais 'explorado' didaticamente, sobretudo em turmas plurilíngues. É verdade que boa parte do que ocorre no processo de aprendizagem nos escapa, inclusive vários aspectos ligados ao papel da miscibilidade na apropriação de uma nova língua. No entanto, postergar ou fazer pouco caso desse fenômeno significa deixar de lado um aspecto relevante de uma competência plurilíngue que é a potencialização da capacidade metalinguística dos alunos. Caso atribuamos somente ao aluno a responsabilidade de fazer esses diálogos entre as línguas, corremos o risco de confundir e/ou de truncar a aprendizagem, ao invés de aproveitar o grande potencial que um repertório plurilíngue pode oferecer. Por exemplo, pode-se dar uma relevância meramente linguística ao fato e esquecer a importância desse repertório para o uso efetivo da língua-alvo numa perspectiva voltada para comunicação. Esse entrelaçar de ações, discursivas

19 Os discursos que circulam no ambiente acadêmico podem ganhar força de dogma, já que a instituição Universidade goza de grande prestígio social. e linguísticas, requer o encaminhamento de alguém experiente para conduzir adequadamente os aprendentes à reflexão e ao uso da língua; por isso o professor é a pessoa mais indicada para esse trabalho. 
Outro risco que corremos se deixarmos essa tarefa metalinguística nas mãos dos alunos é que eles desenvolvam representações equivocadas ou superficiais da língua-alvo. Certamente o aprendente estrutura suas representações sobre o funcionamento do novo sistema a partir do(s) sistema(s) que já internalizou, no caso, sua L1 ou a LR ou ainda outra L2 ou LE. Lembremo-nos do depoimento de uma aluna que afirmou que o português não tem regras. Isso, evidentemente, não é verdade: o português possui muitas regularidades que podem ajudar os falantes dessa língua a produzir novos enunciados a partir do funcionamento de suas estruturas formais. Logo, não devemos deixar solta a estruturação dos sistemas, esperando que os alunos organizem e internalizem tudo 'espontaneamente'. Se o fizermos, estaremos negligenciando o capital metalinguístico que um repertório plurilíngue pode disponibilizar. Ao que tudo indica, foi o que ocorreu com o nosso público-alvo no início do curso. De fato, entrevistados por nós, alguns discentes francófonos afirmaram que o francês não guardava semelhanças com o português. Ao que tudo indica, nesse início de aprendizagem, o repertório linguístico dos alunos francófonos não foi explorado de forma adequada. Sem dúvida, isso é reflexo de uma percepção insuficiente a respeito dos dois sistemas já que ambas as línguas são originárias do latim.

Cabe observar, no entanto, que se as semelhanças entre (pelo menos) uma das línguas do repertório dos aprendentes e a língua-alvo podem facilitar de modo significativo a aprendizagem desta, podem também provocar sua estagnação. Essa foi uma das 'queixas' das alunas que tinham o espanhol como LM. De fato, muitas vezes, devido à grande proximidade linguística entre as duas línguas (Espanhol e Português), há um relaxamento no esforço de aprendizagem, o que pode levar à fossilização da interlíngua, na forma de um uso hibridizado (o portunhol). Um enfoque contrastivo dessa capacidade de reflexão entre línguas pode ser produtivo para aproximar o aprendente de sua língua-alvo e evitar que isso ocorra. Logo, as diferenças também são relevantes nessa atividade comparativa que parece útil para a estruturação da expressão linguística.

Cabe observar ainda que a alternância de línguas tem forte valor didático já que ela mantém o foco dos alunos para o que se quer tratar, subsidiando os inputs em língua-alvo para 
que os alunos possam ter certeza de que estão entendendo o que está sendo trabalhado. Essa ação funciona como balizamento que, se adequadamente utilizado, funciona como andaime (scalffolding) favorecendo assim a aprendizagem da língua-alvo.

Finalmente, reconhecer a alternância é entender que, durante as aulas, os alunos têm o direito de recorrer, pontualmente, a seu repertório linguístico sem sofrer sanções verbais por conta disso. Eles têm o direito de utilizá-lo para tirar uma dúvida, pedir uma explicação, contar um segredo a um colega, expressar algo que só sabem dizer em sua língua de origem, atender uma demanda identitária etc.

\section{Considerações finais}

Tratamos neste artigo de uma realidade bem específica que requer um tratamento diferenciado. As turmas de PLE espalhadas pelo Brasil merecem uma condução didáticometodológica adequada a sua realidade, portanto diferente da maneira como, em geral, o ensino de LE é conduzido nas turmas fortemente homogêneas do ponto de vista cultural e linguístico. A heterogeneidade linguístico-cultural das turmas de PLE põe em xeque práticas que, costumeiramente, eram aceitas pacificamente por muitos na área do ensino-aprendizagem de línguas como, por exemplo, a pouca ou nenhuma serventia da LM e/ou da LR na aprendizagem de uma LE.

Fatores de ordem pluricultural e plurilinguística nesse contexto relativamente novo de pesquisa de ensino de línguas no Brasil nos impõem desafios instigantes que nos induzem a não ignorar determinados traços de sua complexidade. Apontamos aqui para o fato de que questões de cunho cultural precisam ser muito bem gerenciadas pelo professor, caso contrário haverá choques entre aprendentes e, até mesmo, entre aprendente(s) e professor já que todos têm visões de mundo diferentes e, por vezes, bem conflitantes. No entanto, há também questões linguísticas que estão em jogo e possuem especificidades que, se não forem respeitadas, prejudicam o trabalho docente e, consequentemente, a aprendizagem dos discentes. É necessário, portanto, levar em conta os repertórios plurilíngues desses aprendentes, utilizando esse saber, não numa perspectiva compartimentada e estanque, onde cada língua é uma unidade bem delimitada que não dialoga com 
outra língua; mas, pelo contrário, numa perspectiva aberta e dinâmica onde todas dialogam, se inter-relacionam, se misturam facilitando assim a ampliação do repertório dos alunos e o desenvolvimento de sua competência comunicativa.

Todavia, reconhecer a relevância do capital plurilíngue do aluno não significa esquecer que se está diante de uma aula de LE. O que defendemos aqui é um gerenciamento adequado, equilibrado da presença da L1 e/ou da LR ou ainda de outra LE (ou L2) na sala de aula. Entendemos que há momentos em que elas exercem funções suscetíveis de favorecer a aprendizagem (aqui do PLE). Os alunos podem e devem, evidentemente, procurar usar a língua-alvo em sala de aula e fora dela, sem que, para isso, precisem "apagar" as outras línguas durante o processo de aprendizagem.

Parece, pois, indispensável qualificar cada vez mais o professor que atende esse público fornecendo consistente formação de ordem cultural, linguística e didático-pedagógica para que ele possa se postar apropriadamente frente a essa entrelaçada rede de línguas e sentidos. Defendemos a formação de docentes com sensibilidade e preparo adequado para trafegar entre as especificidades culturais e linguísticas de cada aluno ou grupo de alunos.

Finalmente, é importante que se leve em conta a condição na qual esses discentes estrangeiros chegam ao Brasil. Fatores de ordem cultural - país de origem, cultura educativa, posições ideológicas, tolerância no convívio com o diferente -, assim como de ordem linguística - língua(s) que fala, nível de domínio do português... - devem poder nortear melhor as ações didático-pedagógicas. Acreditamos que os fatores aqui levantados são suscetíveis de ajudar a reduzir os impactos dessa mudança na vida desses sujeitos e favorecer sua inserção linguístico-discursiva.

\section{REFERÊNCIAS}

CASTELLOTTI, Veronique. La langue maternelle en classe de langue étrangère. Paris: Clé International, 2000.

(Éd.). D'une langue à d'autres: Pratiques et représentations. Rouen: Presses Universitaires de Rouen, coll. Dyalang, 2001. 
CONSELHO DA EUROPA. Divisão de línguas. Quadro europeu comum de referência para línguas: aprender, ensinar e avaliar. Porto, Portugal: ASA, 2001.

CUNHA, José Carlos; SANTOS, Edirnelis. A heterogeneidade linguístico-cultural em turmas de Português Língua Estrangeira. Raído. Dourados, v. 7, n. 13, p.111-124, jan./jun. 2013. Disponível em : < http://ojs.ufgd.edu.br/index.php/Raido/ article/view/1670/1427 >. Acesso em : 27 dez. 2016.

CUQ, Jean-Pierre (Coord.). Dictionnaire de didactique du français langue étrangère et seconde. Paris: ASDIFLE e CLE International, 2003.

DABÈNE, Louise. Repères sociolinguistiques pour l'enseignement des langues. Paris: Hachette, Collection Références, 1994.

DAHLET, Patrick. Línguas e Identidades: epistemologia da diversidade. MOARA. Revista da Pós-Graduação em Letras da UFPA. Belém, n. 32, p. 13-44, jul./dez. 2009.

Do ensino da língua às (des)apropriações mixilingues. In: MENDES, Edleise; CUNHA, José Carlos (Orgs.). Práticas em sala de aula de línguas: Diálogos necessários entre teoria(s) e ações situadas. Campinas: Pontes Editores, 2012.

LÜDI, George; PY, Bernard. Etrebilingue. Berne: Peter Lang, 2013. MARCUSCHI, Luis Antonio. Análise da Conversação. São Paulo: Ática, 2003.

MOORE, Danièle; PY, Bernard. Parole empruntée, parole appuyée ou la place des emprunts dans l'apprentissage d'une langue seconde. PLURILINGUISMES. Paris, CERPL, no 9/10, p. 133-145, 1995.

WANTZ-BAUER, Fréderique. Le statut de la langue maternelle em cours de langue étrangere: points de vue d'apprenants. In: CASTELLOTTI, Veronique (Éd.). D'une langue à d'autres: Pratiques et représentations. Rouen: Presses Universitaires de Rouen, coll. Dyalang, 2001. 


\section{Abstract \\ Learners' impressions and pressures in the process of appropriation of Portuguese as a foreign language: proficiency and switching languages on a collision course}

Researches about linguistic and cultural heterogeneity in foreign language classes have been helping teachers to suit their teaching practices to the special features of plurilingual and pluricultural students. However, in the Portuguese Foreign Language (PFL) context, this phenomenon has been studied especially from a cultural point of view, leaving aside other equally important aspect of this heterogeneity: the linguistic. Our purpose here is to present the first results of an ethnographic research, focused on the plurilingual reality of a PFL class in the Federal University of Pará (UFPA). The data collected by interview (with students) and teaching actions observations were treated in a qualitative way comprising two moments of reflection: the first take is about contextual aspects and about the individuals; the second is focused on the ways that students deal with their repertoire bi(pluri)lingual, mainly concerning to their linguistic representations and their linguistics actions. On the one hand, the first analyzes show that code-switching is an unavoidable trait in bi(pluri)lingual classes (however, it is often seen as a secret practice that, if caught in the act, is reproached by teacher and discouraged by the classmates) and, on the other hand, an educational resource that, properly dealt, is likely to turn more effective the learning of a language (here, PFL). Hence it's necessary to take into account the linguistic repertoires of these students, using this knowledge in an open and dynamic perspective, leading to the expansion students' communicative competence in the target language.

Keywords: Didactics of plurilingualism. Codeswitching. Linguistic heterogeneity. PFL teaching. 